\title{
EFFECT OF MASS CHEMOTHERAPY AND PIPED WATER ON NUMBERS OF SCHISTOSOMA HAEMATOBIUM AND PREVALENCE IN BULINUS GLOBOSUS IN KWALE, KENYA
}

\author{
SHINICHI NODA, * MASAAKI SHIMADA, $†$ KATSUYUKI SATO, $†$ JOHN H. OUMA,‡ \\ FREDRICK W. THIONGO, NGETHE D. MUHOHO,\& ATSUO SATO,* AND \\ YOSHIKI AOKI† \\ *Department of Medical Zoology, Faculty of Medicine, Kagoshima University, Kagoshima 890, Japan, \\ †Department of Parasitology, Institute of Tropical Medicine, Nagasaki University, Nagasaki 852, \\ Japan, $\ddagger$ Division of Vector Borne Diseases, Ministry of Health, Nairobi, Kenya, and \\ $\$$ Centre for Microbiology Research, Kenya Medical Research Institute, \\ Ministry of Health, Nairobi, Kenya
}

\begin{abstract}
From June 1982 to May 1986 in a small village in Kwale, Kenya, we studied seasonal fluctuations in populations of Bulinus globosus, prevalence of Schistosoma haematobium infection in this snail, and effects of chemotherapy and piped water supply on infection rate of snails. In the perennially-flowing Pemba River, relatively small numbers of snails were collected; they were found only during the hot dry season (December to March). In a tributary stream, the Kadingo River, whose flow ceased at the end of both the cool and hot dry seasons, snail numbers peaked at the end of the cool dry season (October to November) and at the beginning of the hot dry season (January). Large numbers of infected snails were found in the Kadingo River from November to January (short rainy season and beginning of dry season). Selective mass chemotherapy with metrifonate and provision of piped water were begun in February and March 1984. These control measures achieved a significant reduction in the infection rate of snails $(P<0.001)$; the annual infection rate for the 2 years before treatment was $9.3 \%$ and $13.1 \%$, and for the 2 years after treatment was $3.5 \%$ and $3.4 \%$.
\end{abstract}

Additional information on the biology and ecology of intermediate host snails and schistosome transmission is needed to establish general guidelines for control measures applicable in various areas endemic for schistosomiasis. Study of the seasonal fluctuations in snail numbers and associated infection rates may identify the optimum time for applying control measures.

Since 1981 , a research program on urinary schistosomiasis has been carried out at Mwachinga village, Kwale, Kenya, under the joint sponsorship of the Kenya Government and the Japan International Cooperation Agency. Following a baseline 2-year survey, selective mass chemotherapy with metrifonate and provision of piped water were attempted in $1984 ;{ }^{1}$ follow-up studies have continued to date.

The present paper deals with seasonal fluctuations in Bulinus globosus populations, snail infection with Schistosoma haematobium, and the

Accepted 7 December 1987. reduction of infection rates in snails in our study area due to chemotherapy and piped water supply.

\section{MATERIALS AND METHODS}

Snail surveys were carried out twice each month at 13 sites where villagers had frequent contact with water (Fig. 1). Sites 3, 4, 5, and 10 were in the main river (the Pemba River), while sites 13 , $18 \mathrm{~B}, 18 \mathrm{C}, 19,21,22,23,24$, and 29 were located in the adjoining stream (the Kadingo River). Snail collection was carried out at about 0900 hours, when the water temperature of the site was also determined using a glass alcohol thermometer (Iuchi, Osaka). The flow of the river at sites of the snail collection was categorized as flowing, stagnant, or dry. Using a double-layer steel net shovel (4 mm mesh), snails and plants were sampled for $10 \mathrm{~min}$ by one searcher. The number of each species of snail collected was determined and recorded. Water plants collected were examined for egg masses. The height and width of 
each $B$. globosus were measured using a Vernier caliper calibrated to $0.1 \mathrm{~mm}$. Snails were then put into small petri dishes filled with approximately $2 \mathrm{ml}$ of dechlorinated tap water. The petri dishes were kept in a lighted place for more than $2 \mathrm{hr}$, and the water examined for the presence of cercariae under a stereoscopic microscope at $\times 20$ magnification.

The maximum and minimum air temperature were recorded daily with a maximum-minimum thermometer (Iuchi, Osaka) kept in the shade, and rainfall was measured daily with a rain gauge located at the center of the study area.

As we started this project in June 1982, each study year ran from June to May.

\section{RESULTS}

\section{General description of the study area}

Mwachinga village is situated near the Shimba Hills, $5 \mathrm{~km}$ west of Kwale town, which is $30 \mathrm{~km}$ southwest of Mombasa, Kenya. The number of residents registered at the 1982 census was 1,338 , with 617 males and 721 females. Prevalence of infection with $S$. haematobium in 1982 was $68.3 \%$ in all age groups and $99.0 \%$ in the $10-14$ year age group. ${ }^{2}$

The climate may be roughly divided into four seasons: a long rainy season from April to June with peak precipitation in May, a cool dry season from July to October, a short rainy season in November, and a hot dry season from December to March (Fig. 2). The annual rainfall varied from year to year $(503.5-743.8 \mathrm{~mm})$, and the mean annual temperature also varied from year to year $\left(27.0-27.9^{\circ} \mathrm{C}\right)$ (Table 1$)$.

The Pemba River flows through the village, and a stream, the Kadingo River, flows into it in the eastern part of the village (Fig. 1). The Pemba River and the Kadingo River are 5-30 $\mathrm{m}$ and less than $5 \mathrm{~m}$ in width, respectively. Flow of the Pemba River is perennial, but some parts of the Kadingo River dry up in the hot dry season, with subsequent formation of small pools. Towards the end of the dry season, these pools may dry up completely. Because the Pemba River is broad and shallow at site 5, this part of the river may form a pool during the dry season, but the remainder of the sites have flowing water through the entire year. The drop in elevation in the Pemba River within the study area is $\mathbf{3 . 6}$ $\mathrm{m} / \mathbf{k m}$ on average, whereas the Kadingo River

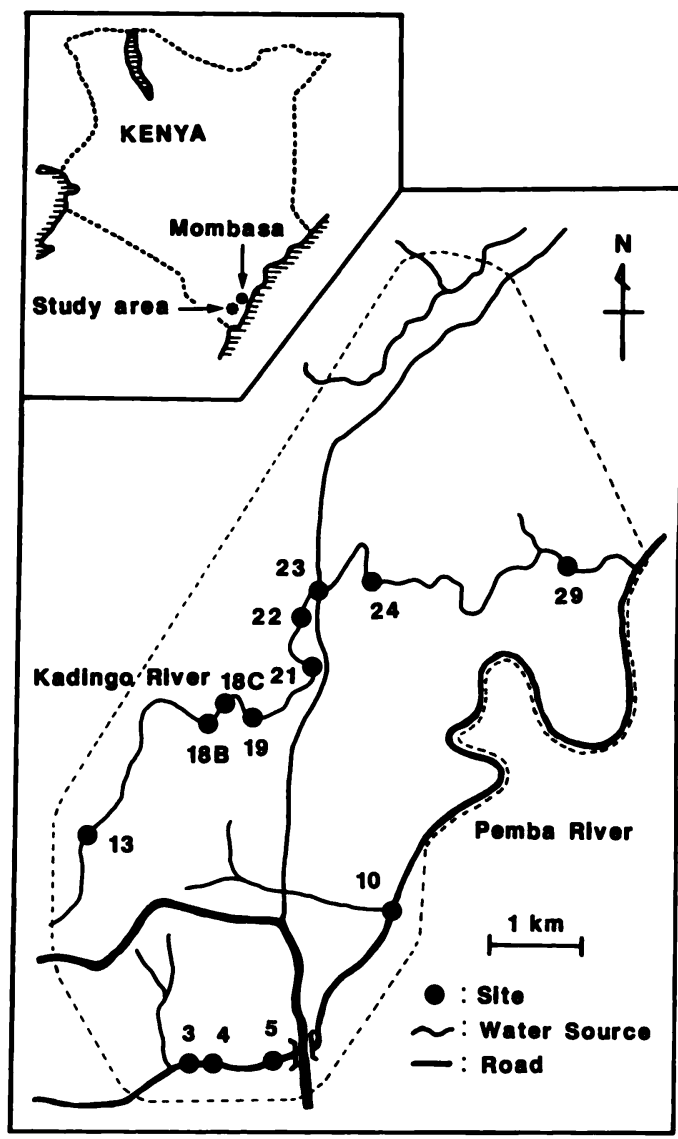

Figure 1. Study area.

drops $6.7 \mathrm{~m} / \mathrm{km}$ upstream of site 19 , and $3.6 \mathrm{~m} /$ km downstream of the same site.

\section{Seasonal fluctuation of snail population}

The number of $B$. globosus collected at the 13 sites from June 1982 to May 1986 is shown in Table 1. The number of these snails collected varied from site to site and from year to year. Relatively few snails were collected from the Pemba River, $80.9 \%(1,354 / 1,674)$ being collected at site 5 . Based on the number of sites, $B$. globosus populations in the Kadingo River (12,026 snails, 9 sites) were approximately $3-4$ times those in the Pemba River (1,674 snails, 4 sites). However, within the Kadingo River, some habitats were better than others for supporting snail populations. Sites $18 \mathrm{C}, 19$, and 22 contained relatively high populations of molluscs; sampling areas $21,23,24$, and 29 supported 


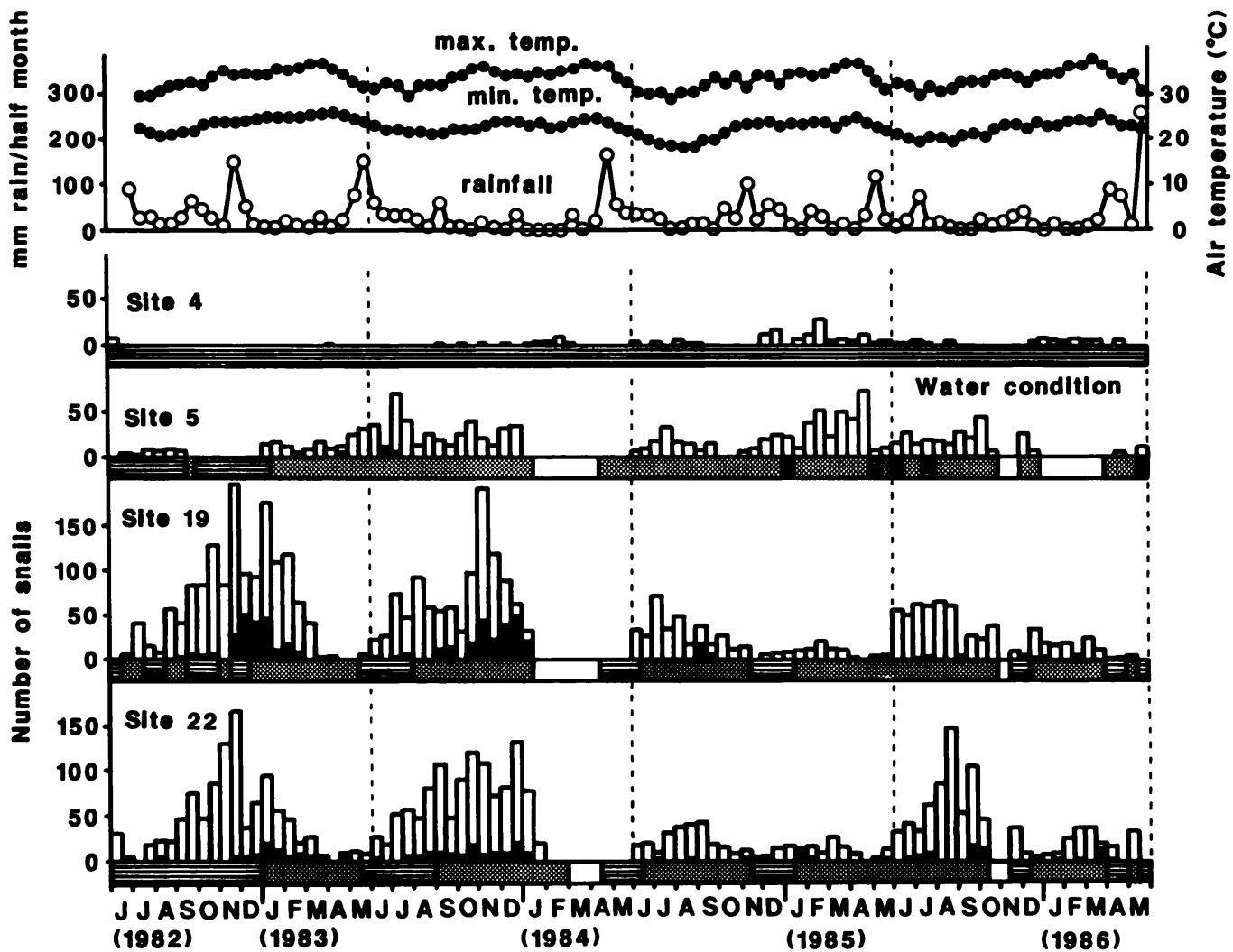

FIGURE 2. Temperature and rainfall in the study area and number of $B$. globosus collected (open column) and infected snails (black column) at sites $4,5,19$, and 22 , in relation to water level (E: flowing, 国: no flow, $\square$ : dry).

smaller populations; and habitats 13 and $18 \mathrm{~B}$ had few snails. Also evident from the data is, that with the exception of site 24 , there was 25 -fold variation in annual snail abundance. We have no explanation for the exceptionally high degree of variability in snail numbers at site 24 . Additionally, total snail numbers in both the Pemba and Kadingo rivers fluctuated with yearly rainfall so that we have two sets of data which mirror each other. Maximum numbers of snails in the Pemba River and minimum numbers in the Kadingo River were detected in year 3 of the study when total rainfall was $594 \mathrm{~mm}$. The regression curves which show the relation between the annual rainfall and number of snails in the Pemba and Kadingo rivers are shown in Figure 3. The regression equations were calculated as follows:

For the Pemba River:

$$
\begin{aligned}
Y(\text { number of snails })= & 23.01 X-0.019 X^{2} \\
& -6,183.29
\end{aligned}
$$

where $\mathrm{X}=$ rainfall, $\mathrm{r}^{2}$ for the equation is 0.837 or $\mathbf{r}=0.91$.

For the Kadingo River:

$$
Y=-148.132 X+0.1221 X^{2}+46,839.77 \text {, }
$$

$r^{2}$ for the equation is 0.957 or $r=0.98$.

During years 3 and 4 when control measures were in effect, total number of $B$. globosus collected in the Kadingo River was 5,665, as compared to years 1 and 2, when a total of 8,035 snails was collected. This decline following implementation of control is fortuitous and cannot be attributed directly to control measures.

Monthly fluctuations in snail populations at four different observation sites, two from the Pemba River and two from the Kadingo River, 
TABLE 1

Annual population of B. globosus collected at each site

\begin{tabular}{|c|c|c|c|c|c|c|c|c|c|c|c|c|}
\hline \multirow{5}{*}{$\begin{array}{l}\text { Rainfall (mm): } \\
\text { Mean air } \\
\text { temperature ('C): }\end{array}$} & \multicolumn{12}{|c|}{ Year of collection } \\
\hline & \multicolumn{3}{|c|}{1} & \multicolumn{3}{|c|}{2} & \multicolumn{3}{|c|}{3} & \multicolumn{3}{|c|}{4} \\
\hline & \multicolumn{3}{|c|}{743.8} & \multicolumn{3}{|c|}{503.5} & \multicolumn{3}{|c|}{594.3} & \multicolumn{3}{|c|}{682.8} \\
\hline & \multicolumn{3}{|c|}{27.0} & \multicolumn{3}{|c|}{27.9} & \multicolumn{3}{|c|}{27.5} & \multicolumn{3}{|c|}{27.5} \\
\hline & \multirow{2}{*}{$\begin{array}{l}\text { No. of } \\
\text { snails }\end{array}$} & \multicolumn{2}{|c|}{ Infected } & \multirow{2}{*}{$\begin{array}{l}\text { No. of } \\
\text { snails }\end{array}$} & \multicolumn{2}{|c|}{ Infected } & \multirow{2}{*}{$\begin{array}{l}\text { No. of } \\
\text { snails }\end{array}$} & \multicolumn{2}{|c|}{ Infected } & \multirow{2}{*}{$\begin{array}{l}\text { No. of } \\
\text { snails }\end{array}$} & \multicolumn{2}{|c|}{ Infected } \\
\hline Site & & No. & $\%$ & & No. & $\%$ & & No. & $\%$ & & No. & $\%$ \\
\hline \multicolumn{13}{|l|}{ Pemba River } \\
\hline $\begin{array}{r}3 \\
4 \\
5 \\
10\end{array}$ & $\begin{array}{r}3 \\
8 \\
187 \\
3\end{array}$ & $\begin{array}{l}0 \\
0 \\
4 \\
0\end{array}$ & 2.1 & $\begin{array}{r}25 \\
402 \\
0\end{array}$ & $\begin{array}{r}0 \\
3 \\
13 \\
0\end{array}$ & $\begin{array}{r}12.0 \\
3.2\end{array}$ & $\begin{array}{r}78 \\
109 \\
509 \\
0\end{array}$ & $\begin{array}{l}0 \\
0 \\
0 \\
0\end{array}$ & & $\begin{array}{r}28 \\
39 \\
256 \\
17\end{array}$ & $\begin{array}{l}0 \\
3 \\
0 \\
1\end{array}$ & $\begin{array}{l}7.7 \\
5.9\end{array}$ \\
\hline Total & 201 & 4 & 2.0 & 437 & 16 & 3.7 & 696 & 0 & & 340 & 4 & 1.2 \\
\hline \multicolumn{13}{|c|}{ Kadingo River } \\
\hline $\begin{array}{l}13 \\
18 \mathrm{~B} \\
18 \mathrm{C} \\
19 \\
21 \\
22 \\
23 \\
24 \\
29\end{array}$ & $\begin{array}{r}18 \\
15 \\
888 \\
1,470 \\
247 \\
1,051 \\
166 \\
9 \\
251\end{array}$ & $\begin{array}{r}0 \\
1 \\
87 \\
214 \\
21 \\
58 \\
6 \\
0 \\
9\end{array}$ & $\begin{array}{r}6.7 \\
9.8 \\
14.6 \\
8.5 \\
5.5 \\
3.6\end{array}$ & $\begin{array}{r}16 \\
37 \\
377 \\
1,068 \\
183 \\
1,144 \\
142 \\
38 \\
277\end{array}$ & $\begin{array}{r}1 \\
2 \\
38 \\
228 \\
29 \\
91 \\
6 \\
5 \\
71\end{array}$ & $\begin{array}{r}6.3 \\
5.4 \\
10.1 \\
21.3 \\
15.8 \\
8.0 \\
4.2 \\
13.2 \\
25.6\end{array}$ & $\begin{array}{r}28 \\
42 \\
449 \\
460 \\
184 \\
401 \\
40 \\
38 \\
92\end{array}$ & $\begin{array}{r}2 \\
5 \\
8 \\
31 \\
24 \\
12 \\
2 \\
0 \\
1\end{array}$ & $\begin{array}{r}7.1 \\
11.9 \\
1.8 \\
6.7 \\
13.0 \\
3.0 \\
5.0\end{array}$ & $\begin{array}{r}17 \\
80 \\
559 \\
613 \\
178 \\
857 \\
154 \\
384 \\
53\end{array}$ & $\begin{array}{r}0 \\
4 \\
24 \\
6 \\
1 \\
54 \\
1 \\
15 \\
2\end{array}$ & $\begin{array}{l}5.0 \\
4.3 \\
1.0 \\
0.6 \\
6.3 \\
0.6 \\
3.4 \\
3.8\end{array}$ \\
\hline Total & 4,115 & 396 & 9.6 & 3,282 & 471 & 14.4 & 1,734 & 85 & 4.9 & 2,895 & 107 & 3.7 \\
\hline Grand total & 4,316 & 400 & 9.3 & 3,719 & 487 & 13.1 & 2,430 & 85 & 3.5 & 3,235 & 111 & 3.4 \\
\hline
\end{tabular}

are shown in Figure 2. At site 4 (main river; perennial flow), only a small number of snails was collected, exclusively in the hot dry season from December to March, when river flow was at a minimum. At site 5 (main river; pool in dry season), the number of snails collected fluctuated greatly during the year and the time of peak population changed from year to year. This variability seems to be correlated with the presence or absence of water and flow in that site in previous months. For example, peak numbers at site 5 in the second year (June 1983 to May 1984) occurred after approximately 6 months of still water conditions which had been preceded by flowing water conditions. However, in the third year (June 1984 to May 1985), the site was dry for 3 months during the previous dry season, and then in January 1985, increased rainfall turned the site into a flowing water habitat for a half month. Both of these events appeared to have delayed development of a stable habitat. Population peaks in the two sites in the Kadingo River are associated with the alternating cycles of rainy and dry season. With the end of the long rainy season, the snail populations in habitats 19 and
22 started to increase (June), reached a peak (October-November), and fell during the drought or with the onset of the short rainy season (November). Numbers rose again with the cessation of flowing water and reached a peak (January), then decreased during the drought to a low level (March). The second peak was lower than the first and was not observed in the second year of the study, probably because of little rain in the short rainy season. The same seasonal fluctuation in the snail populations was observed in the other sites located in the Kadingo River.

The size distribution of snails collected at site 19 in the first year of the study is shown in Figure 4. After the long rainy season, only juvenile snails were found. In November, December, and January, most of the snails collected were adults. However, smaller snails were collected again in January and February. The juveniles found after the long rainy season were probably the descendants of the few remaining adults in the habitat at the end of flooding caused by the rainy season. These juveniles matured and some were swept away by the increased river flow during the short rainy season. However, populations were aug- 


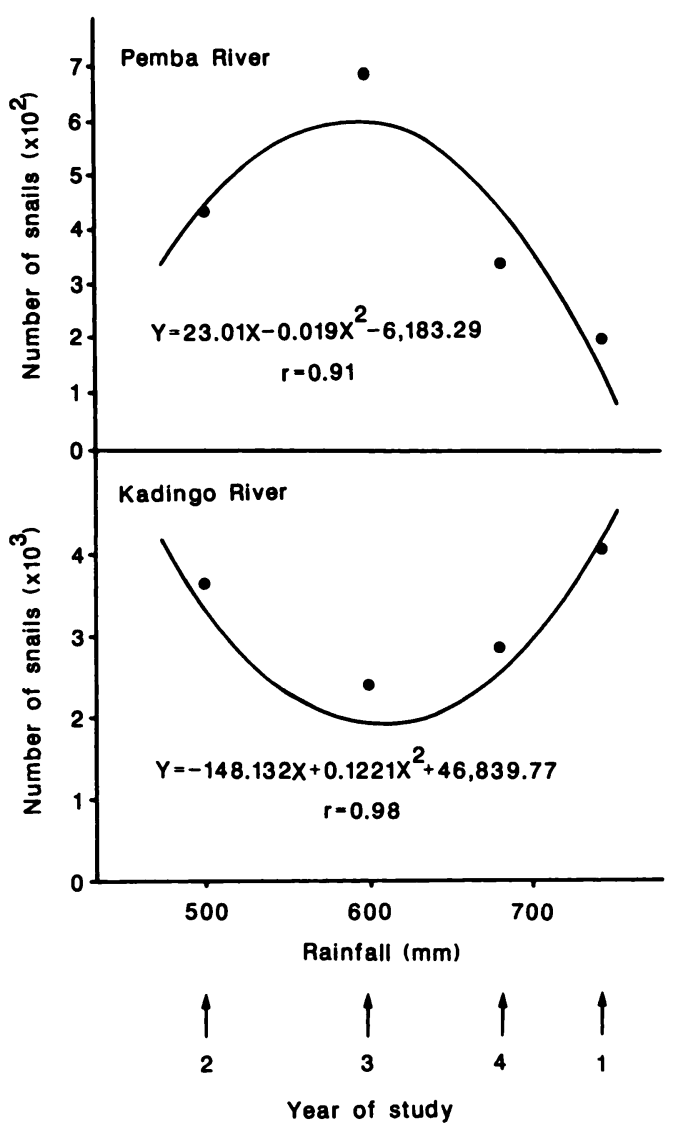

FIGURE 3. Correlation between annual rainfall and number of $B$. globosus at the Pemba River and the Kadingo River.

mented by production of a new generation of $B$. globosus. As the dry season progressed, habitats contracted with subsequent cessation of egg-laying and eventual death of the molluscs.

Egg masses were frequently present whenever snails were collected, but we failed to identify either the species of egg masses or any seasonal variations in their number.

We did not detect any significant correlation between snail density and water temperature. However, this lack of correlation may have been due to the fact that we did not determine water temperatures at a time when they would have been at their maxima.

In addition to $B$. globosus, five other snail species were collected in the study area. The thiarids Cleopatra africana and Cleopatra bulimoides and the ampullariid Lanistes ovum procerus were collected in both rivers, while the thiar-

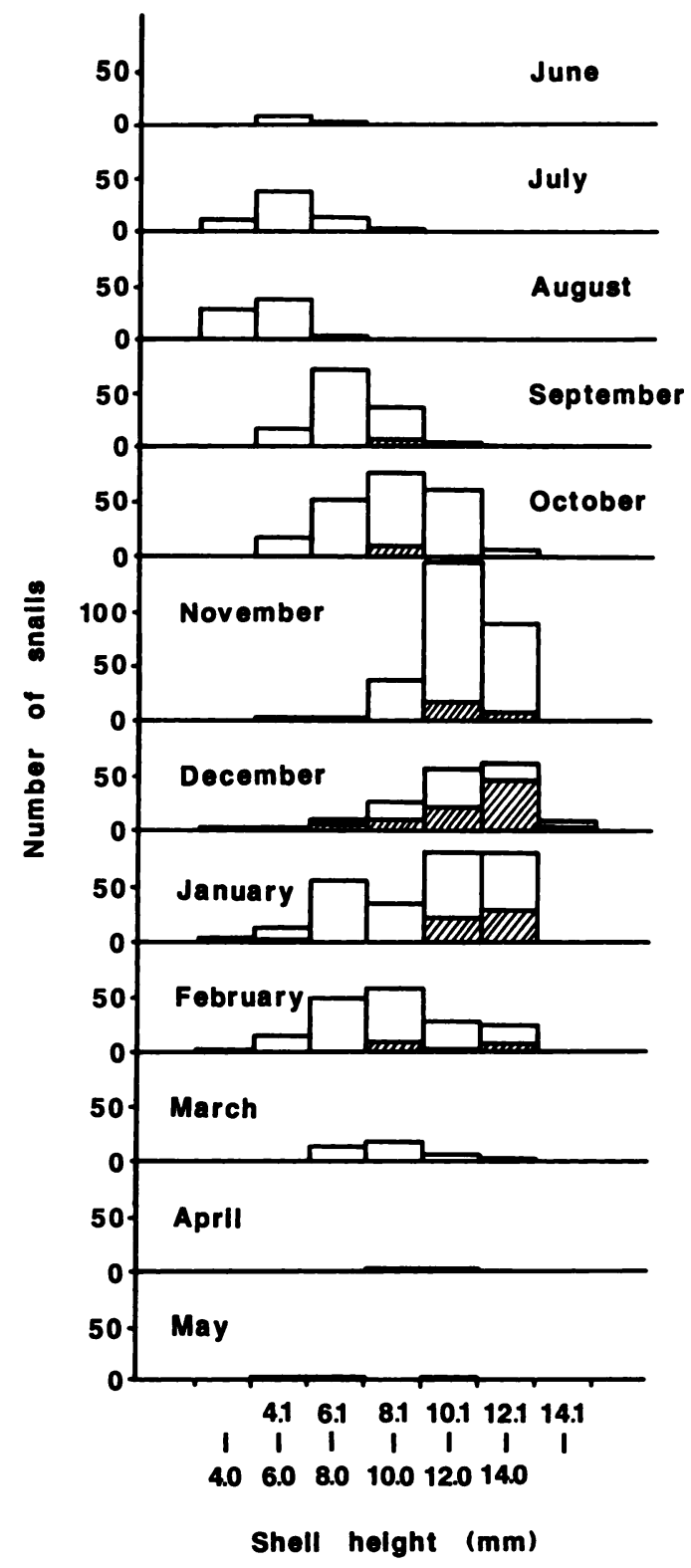

FIGURE 4. Shell height distribution of B. globosus and infection with $S$. haematobium (hatched column) at site 19, June 1982 to May 1983.

id Melanoides tuberculata and the viviparid Bellamya unicolor were found only in the Pemba River.

Rate of infection in B. globosus

Infected snails were collected at all sites except habitat 3, which was located in the Pemba River 
(Table 1). In general, infection rates were higher at sites of the Kadingo River than those of the Pemba River. Over the entire duration of the project, only 24 infected snails were collected from the Pemba River with $70.8 \%$ (17/24) coming from habitat 5 . In contrast, 1,059 infected snails were found in the Kadingo River with $87.4 \%(926 / 1,059)$ of these derived from sites $18 \mathrm{C}, 19,21$, and 22 . However, in years 2 and 4 of the study, $15 \%$ and $14 \%$ of infected snails from the Kadingo River were found in sites 29 and 24 , respectively. The overall infection rates in the first and second years of the study in the Kadingo River were $9.6 \%$ and $14.4 \%$, respectively (Table 1) with a 2-year overall prevalence of $11.7 \%(867 / 7,397)$. In the Pemba River, overall rates were $2.0 \%$ and $3.7 \%$ with a 2 -year mean prevalence of $3.1 \%(20 / 638)$.

In the Kadingo River, the majority of infected snails was collected from October to January; the transmission potential (number of infected snails collected in a period divided by the total number of infected snails collected during a year) of these 4 months in the first and second study years was $80.5 \%$ and $76.1 \%$, respectively. Infections were found only in larger snails, and high infection rates were associated with the presence of a large proportion of adult snails (Fig. 4).

\section{Reduction of infection rate of B. globosus following control measures}

Selective mass chemotherapy with metrifonate and the introduction of piped water supply were carried out in February and March 1984. Subsequently, the geometric mean of egg output fell from 46.5 to 9.4 eggs $/ \mathrm{hr}$ ( $80 \%$ reduction) in all age groups.' Chemotherapy and piped water supply also caused a remarkable reduction in the infection rate of snails, so seasonal variations in the infection rate of snails in the side stream became less discernible. The overall infection rate in the first and second years of the study (before control) was $9.3 \%$ and $13.1 \%$, and the rate in the third and fourth years of the study (after control) was $3.5 \%$ and $3.4 \%$, respectively (Table 1 ). This reduction of the infection rate is significant at the 0.001 probability level ( $\chi^{2}$ statistic).

\section{DISCUSSION}

The distribution and population of intermediate host snails may be affected by many factors such as the size of habitat, water level, current velocity, temperature, light, chemical composition of water, microflora, and fauna. Our study suggested that populations of $\boldsymbol{B}$. globosus varied both temporally and spatially. The major determinant of snail number in our endemic zone seems to be both total rainfall and pattern of rainfall as demonstrated by Table 1 and Figures 2 and 3.

The annual rainfall exerted different effects on the snail populations at different habitats in our study area. In year 1 of the study, when total rainfall was $744 \mathrm{~mm}$, minimum and maximum numbers of snails were observed in the Pemba River and in the Kadingo River, respectively. In year 3 of the study, when total rainfall was 594 $\mathrm{mm}$, maximum numbers of snails were detected in the Pemba River and minimum numbers were found in the Kadingo River. The regression curve which shows the relation between the annual rainfall and number of snails in the Pemba River mirrors that in the Kadingo River (Fig. 3). One explanation of these graphs is that colonies of snails were deleted from the habitat by unexpected natural disasters. ${ }^{3}$ For the Pemba River, where site 5 supported the greatest number of snails, excessive rainfall probably flushed snails out of the habitat, and scanty rainfall caused site 5 to dry up. Therefore, both excessive and scanty annual rainfall adversely affected snail numbers in the Pemba River. Snail habitats of the Kadingo River dry during the hot dry season with subsequent formation of small pools. Some pools disappear completely by the end of the dry season. Increased annual rainfall will retard complete drying of such pools. Therefore, snail populations in the Kadingo River are likely to increase with annual rainfall. However, we cannot explain why year 2 (rainfall $504 \mathrm{~mm}$ ) produced more snails than did year 3 (rainfall $594 \mathrm{~mm}$ ).

The pattern of rainfall, which is closely correlated with the water level of the habitat, may regulate seasonality of snail populations. In the Pemba River, snail populations are kept at a low level by high flows due to the rainy season, and the snails were collected mainly in the hot dry season when river flow was minimal. Similar seasonal fluctuations in populations of $B$. globosus were reported at a perennial stream on the coast of Kenya. ${ }^{4}$ Our data suggest that in lotic habitats, most $B$. globosus are located in areas where natural decreases in stream velocity occur. In the Kadingo River, the population of snails showed a more intimate association with the alternating cycle of rainy and dry season; marked temper- 
ature changes also occur in association with these seasons. At the end of the long cool rainy season (June-July), snail population started to increase. This may be due to the start of oviposition by the adult snails which successfully estivated during the dry season. ${ }^{5.6}$ The snail population peaked in October-November and fell with the onset of the short rainy season (November). The number of snails rose again at the end of the hot short rainy season, and reached a peak (January), then decreased during the drought to a low level. The same seasonal changes of $B$. globosus population were observed in the dam at Bamburi, in the coastal area of Kenya, and in a pond at Mlingano, Tanzania; ${ }^{5.7}$ populations of $B$. nasutus and $B$. africanus also showed a similar fluctuation pattern.' Some sites of the Kadingo River were densely populated by snails, but other sites were not. Favorable habitats are parts of the river which are flat-bottomed and deep, and which still contain water at the end of the dry season. Less favorable habitats are parts of the river which have a gentle slope and are shallow; such locations completely dried up during the dry season. The location of favorable sites may vary from year to year due to the pattern of rainfall. In year 4 , an unexpected 10-fold increase of the snail population was observed in habitat 24 . Such a habitat may be important as a reservoir of transmission and infection after control.

Precise definition of the season of transmission in the endemic area is essential for planning effective control measures. Transmission is largely influenced by temperature and rainfall. As low water temperature retards development of miracidia into cercariae, the potential of transmission is low during cool seasons. ${ }^{8.9}$ In Volta Lake, the season and locality of transmission of $S$. haematobium by $B$. truncatus rohlfsi have been established in relation to annual changes of lakelevel and associated vegetation changes in human water contact sites. ${ }^{10,11}$ In our study area, the period between December and January (hot dry season) is the time when disease transmission potential is highest. This is probably explained by the fact that infections were found exclusively in larger snails, and that such snails were relatively abundant during this period. Snails probably do not produce cercariae until they are about $10 \mathrm{~mm}$ in height. From the time of oviposition, approximately 80-100 days are required for snails to reach $10 \mathrm{~mm}$ in size. ${ }^{12,13}$

Infected snails were more frequently found in the Kadingo River than in the Pemba River. The infection rate of snails in the Pemba River seems to be affected by stream velocity and water volume. When sentinel snails were exposed to miracidia in a natural situation, no infections were found when water velocity exceeded $13 \mathrm{~cm} / \mathrm{sec}^{14}$

Chemotherapy plays an important role in the control of schistosomiasis. ${ }^{15}$ The new effective and safe drugs make it theoretically possible to reduce the level of infection to the break point. ${ }^{16}$ Success depends on the extent of population compliance in the endemic area. In our study area, chemotherapy with metrifonate and piped water supply to the villagers were selected as control measures. As our study disclosed that transmission of $S$. haematobium by $B$. globosus mainly occurred from October to January, selective mass chemotherapy with metrifonate was carried out just after the season of transmission, February and March 1984.' Out of 813 villagers to be treated, a total of 690 accepted treatment. Some villagers, however, inevitably remained as a reservoir of infection. At the same time, 5 water kiosks (community water supply points) were constructed in the study area to reduce human contact with cercarial infested water, and 1 shower shed was also constructed in the primary school to reduce the bathing and playing of schoolchildren in the river. A follow-up study revealed that 1 year later the overall infection rate in B. globosus had fallen to $30 \%$ of the previous level, and 2 years later the rate remained low. The lower infection rate of snails probably reflected the fact that the intensity of the infection in our study area remained low. The intensity of infection in the community was reduced from $\mathbf{4 6 . 5}$ eggs/ $\mathrm{hr}$ to $9.4 \mathrm{eggs} / \mathrm{hr}$ by treatment,' and it was $11.6 \mathrm{eggs} / \mathrm{hr}$ at the examination done 28 months after the treatment (E. Kimura, personal communication). In St. Lucia, the incidence of new infections was reduced after each household was provided with its individual water supply and community laundry shower units were made available; water supply appeared to be effective in maintaining transmission at a low level during the post-chemotherapy maintenance phase of the control program. ${ }^{17}$ Provision of community water supply also reduced prevalence and intensity of infection. ${ }^{18-20}$ In Egypt, it was noted that even the partial use of protected water markedly lowered the rates of infection. ${ }^{18}$ In South Africa, a gradual reduction of infection rates followed the introduction of environmental control measures: piped water on a communal basis, swimming facilities, and prevention of access to dangerous 
water. ${ }^{19}$ In Brazil, human infection rates were progressively reduced by environmental sanitation, and by provision of well water, laundry and showers, and latrines. ${ }^{20}$ The community water supply system constructed in our study area not only reduced human contact with cercarial infested water but also diminished the number of uncooperative villagers who refused examination and treatment. Uncooperative persons were considered to be an important reservoir of infection.

In St. Lucia, no infected sentinel or wild snails were found after a selective population chemotherapy campaign. However, wild snails subsequently became infected, transmission recurred, and prevalence increased..$^{21-23}$ In our study area, the overall infection rate of snails in the third and fourth years of the study (after control) was $3.5 \%$ and $3.4 \%$, respectively, and intensity of infection increased slightly. These facts showed that transmission persisted at a low level after chemotherapy and provision of piped water in our study area. Moreover, immigration into Mwachinga increased sharply after control efforts were initiated. A total of 156 persons from June 1982 to March 1984, and 395 from April 1984 to October 1986 moved to this area. It is apparent that additional control efforts will be required in this area, so follow-up studies have continued. Prevalence and intensity of infection with $S$. haematobium after chemotherapy and piped water supply, particularly in relation to water contacts of villagers, are under analysis.

\section{ACKNOWLEDGMENTS}

We are indebted to M. Mugambi, Director of Kenya Medical Research Institute, for permission and encouragement to carry out this study. We are grateful to P. Waiyaki, Director of the Centre for Microbiology Research, and D. Koech, Director of Biomedical Sciences Research Centre, for their cooperation during the survey. Our thanks are due to E. S. Loker, University of New Mexico, for reading the manuscript.

This paper is published with the permission of the Publications Committee of Kenya Medical Research Institute. The publication of this paper was supported by the Kodama Memorial Fund for Medical Science Research.

\section{REFERENCES}

1. Sato, K., Shimada, M., Noda, S., Muhoho, N. D., Katsumata, T., Sato, A., and Aoki, Y., 1988.
Efficacy of metrifonate in a highly endemic area of urinary schistosomiasis in Kenya. Am. J. Trop. Med. Hyg., 38: 81-85.

2. Shimada, M., Hirata, M., Sato, K., Noda, S., Aoki, Y., Bebora, G., Tosha, S., Wambayi, E., Ouma, J., and Koech, D. K., 1984. Quantitative observation of Schistosoma haematobium infection in Kwale District, Coast Province, Kenya. Proc. Fifth Ann. Med. Sci. Conf., Nairobi, Kenya.

3. Jordan, P., Christie, J. D., and Unrau, G. O., 1980 Schistosomiasis transmission with particular reference to possible ecological and biological methods of control. Acta Trop., 37: 95-138.

4. Teesdale, C., 1962. Ecological observations on the molluscs of significance in the transmission of bilharziasis in Kenya. Bull. WHO, 27: 759782.

5. Webbe, G., and Masangi, A. S., 1958. Observations on three species of Bulinus on the east coast of Africa. Ann. Trop. Med. Parasitol., 52: 302 314.

6. Webbe, G., 1962. The transmission of Schistosoma haematobium in an area of Lake Province, Tanganyika. Bull. WHO, 27: 59-85.

7. O'Keeffe, J. H., 1985. Population biology of the freshwater snail Bulinus globosus on the Kenya coast. I. Population fluctuations in relation to climate. J. Appl. Ecol., 22: 73-84.

8. Chu, K. Y., Massoud, J., and Sabbaghian, H., 1966. Host-parasite relationship of Bulinus truncatus and Schistosoma haematobium in Iran. 4. Effect of month of infection on cercarial-incubation periods of $S$. haematobium and $S$. bovis. Bull. WHO, 34: 135-140.

9. Shiff, C. J., Yiannakis, C., and Eardley, M., 1975. Seasonal influence on the production of Schistosoma haematobium and $S$. mansoni cercariae in Rhodesia. Int. J. Parasitol., 5: 119-123.

10. Chu, K. Y., and Vanderburg, J. A., 1976. Techniques for estimating densities of Bulinus truncatus rohlfsi and its horizontal distribution in Volta Lake, Ghana. Bull. WHO, 54: 411-416.

11. Klumpp, R. K., and Chu, K. Y., 1977. Ecological studies of Bulinus rohlfsi, the intermediate host of Schistosoma haematobium in the Volta Lake. Bull. WHO, 55: 715-730.

12. Marti, H., 1986. Field observations on the population dynamics of Bulinus globosus, the intermediate host of Schistosoma haematobium in the Ifakara area, Tanzania. J. Parasitol., 72. 119-124.

13. O'Keeffe, J. H., 1985. Population biology of the freshwater snail Bulinus globosus on the Kenya coast. II. Feeding and density effects on population parameters. J. Appl. Ecol., 22: 85-90.

14. Upatham, E. S., 1973. Location of Biomphalaria glabrata (Say) by miracidia of Schistosoma mansoni Sambon in natural standing and running water in the West Indian island of St. Lucia. Int. J. Parasitol., 3: 289-297.

15. World Health Organization, 1985. The control of schistosomiasis. Report of a WHO Expert Committee. WHO Tech. Rep. Ser. No. 728.

16. Macdonald, G., 1965. The dynamics of helminth infections, with special reference to schisto- 
somes. Trans. R. Soc. Trop. Med. Hyg., 59: 489-506.

17. Jordan, P., Unrau, G. O., Bartholomew, R. K., Cook, J. A., and Grist, E., 1982. Value of individual household water supplies in the maintenance phase of a schistosomiasis control programme in Saint Lucia, after chemotherapy. Bull. WHO, 60: 583-588.

18. Farooq, M., Nielsen, J., Samaan, S. A., Mallah, M. B., and Allam, A. A., 1966. The epidemiology of Schistosoma haematobium and $S$. mansoni infections in the Egypt-49 project area. Bull. WHO, 35: 319-330.

19. Pitchford, R. J., 1970. Further observations on bilharzia control in the Eastern Transvaal. $S$. Afr. Med. J., 44: 475-477.

20. Barbosa, F. S., Pinto, R., and Souza, O. A., 1971.
Control of schistosomiasis mansoni in a small north east Brazilian community. Trans. $R$. Soc. Trop. Med. Hyg., 65: 206-213.

21. Christie, J. D., and Upatham, E. S., 1977. Control of Schistosoma mansoni transmission by chemotherapy in St. Lucia. II. Biological results. Am. J. Trop. Med. Hyg., 26: 894-898.

22. Barnish, G., 1982. Evaluation of chemotherapy in the control of Schistosoma mansoni in Marquis Valley, Saint Lucia. II. Biological results. Am. J. Trop. Med. Hyg., 31: 111-115.

23. Jordan, P., Bartholomew, R. K., Grist, E., and Auguste, E., 1982. Evaluation of chemotherapy in the control of Schistosoma mansoni in Marquis Valley, Saint Lucia. I. Results in humans. Am. J. Trop. Med. Hyg., 31: 103-110. 